\title{
The Effect of Limited Counseling Time on Hearing Aid Uptake
}

\author{
Heil Noh ${ }^{1}$, Hyunyong Lee ${ }^{2}$, Soo-Hyeong Lee ${ }^{1}$, Gibeom Ko ${ }^{1}$, In-Hye Kim ${ }^{1}$, and Rae-Hyung Kim ${ }^{1}$ \\ ${ }^{1}$ Department of Otolaryngology, The Catholic University of Korea College of Medicine, St. Vincent's Hospital, Suwon; and \\ ${ }^{2}$ Clinical Research Coordinating Center, Catholic Medical Center, The Catholic University of Korea, Seoul, Korea
}

\section{보청기 결정에 제한된 상담 시간이 미치는 영향}

\author{
노혜일 ${ }^{1} \cdot$ 이현용 $^{2} \cdot$ 이수형 $^{1} \cdot$ 고기범 $^{1} \cdot$ 김인혜 $^{1} \cdot$ 김래형 $^{1}$ \\ 가톨릭대학교 의과대학 성빈센트병원 이비인후과학교실, ${ }^{1}$ 가톨릭대학교 의과대학 임상연구지원센터 통계지원실 ${ }^{2}$
}

Received August 22, 2016

Revised October 18, 2016

Accepted October 18, 2016

Address for correspondence

Heil Noh, MD

Department of Otolaryngology,

The Catholic University of Korea

College of Medicine,

St. Vincent's Hospital,

93 Jungbu-dearo, Paldal-gu,

Suwon 16247, Korea

Tel +82-31-249-7450

Fax $+82-31-257-3752$

E-mail hinoh@catholic.ac.kr
Background and Objectives To determine appropriate counseling time for the first hearing aids user, we measured the effectiveness of first counseling time limit of 20 minutes for those who need hearing aids and collected predictive parameters during history taking.

Subjects and Method We reviewed the medical records of 956 patients (age $66.5 \pm 12.1$ ) with hearing impairment who needed hearing aids. We divided patients into two groups, those who had counseling time limited to 20 minutes and others who had no time limitation. Job status, working condition of noise status, social activity and audiological variables were analyzed as probable predicting factors influencing the purchasing of the hearing aid (penetration rate). Results Of the total 956 patients, $48.64 \%$ of subjects decided to purchase hearing aids at first counseling. The two groups showed no significant difference $(p=0.396): 49.81 \%$ of the group without time limitation purchased the hearing aid and $47.04 \%$ of those with time limitation purchased the aid. The social status, right side pure tone threshold and right side tinnitus were significant for calculating the explanation power (64.15\%) in the hearing aid uptake probability equation.

Conclusion The level of social activity, hearing threshold and tinnitus were predictive variables obtained during the counseling. The time limitation of 20 minutes did not affect the rate of decision to purchase hearing aids. These results might help hearing clinics improve efficient time management at hearing aid clinics.

Korean J Otorhinolaryngol-Head Neck Surg 2017;60(1):13-8

\section{서 론}

시간에 쫓기는 외래 진료 환경에서, 보청기 상담 시 어느 정도의 첫 상담 시간이 적절한지에 대한 체계적인 연구는 찾 기가 어려웠다. 이는 국가별로 진료 환경이 다르고 시간을 충 분히 들여야 함에는 공감하지만 현실적 제약이 따르기 때문 일 것이라 생각한다.

미국의 경우에 Kochkin ${ }^{1)}$ 은 상담 시간이 길어질수록 환자 들의 만족도는 높아지고 새로운 환자를 상담할 때 소요되는
평균시간은 대부분 30 분 이상이었다고 보고하였다. 두 번에 걸쳐 한 시간씩 상담을 하면 상담을 하지 않은 경우보다 설문 지를 이용한 만족도 조사에서 좋은 결과를 얻었다는 연구도 있었고, ${ }^{2}$ 이명과 관련된 보청기 상담에는 1 2시간이 필요하다 고 하였다. ${ }^{3)}$ 그러나 국내 현실에서 이 정도의 긴 상담은 비효 율적이라고 판단하였고, 적절한 시간 조정을 위해 첫 상담(prefitting counseling)에 시간 제한을 두어, 상담 시간 제한이 보청기 결정에 영향을 미치는지 알고자 하였다.

보청기 클리닉에서 난청 환자들에게 보청기를 맞추어 주는 
과정은 3 4번의 방문이 필요하며, ${ }^{4)}$ 매번 상담 과정을 거친다. ${ }^{5)}$ 그중에서 첫 상담의 목적은 보청기가 필요한 환자에게 충분 한 정보를 제공하여 적절한 선택을 유도하는 것이다. 또한 보 청기를 체험하게 하여 상담을 통해 잘못된 인식을 개선시킬 수 있다. 보청기를 선택하는 데 부정적 영향을 미치는 요소는 외형적 거부감(cosmetics and stigma)이 중요하다.5) 이러한 감 정적인 문제가 아닌 경우에, 보청기의 필요성을 공감하는 난 청 환자들에서 구입 결정에는 경제적인 이유가 중요한 변수 이다. 그러나 상담 과정 중 환자나 보호자의 경제적 여건을 직 접적으로 파악하기는 현실적으로 어렵고 경제적인 문제는 직 접적인 도움을 줄 수 없으므로 비용 문제로 장시간 상담을 하는 것은 큰 의미가 없었다. Moon 등의 연구에서 의료기관 의 이비인후과 전문의에 의한 체계적인 처방과 관리가 성공적 인 보청기 재활에 중요한 변수임을 시사하였고, 이를 위해 시 간 효율 문제는 임상에서 해결해야 할 중요한 부분이라 생각 한다. 그러므로 경제적인 요인 외에 다른 요인들을 분석하여 예측 가능한 변수들을 알아낸 후에는 더 긴 시간을 투자하여 보청기를 하도록 설득하는 것이 의미가 없다고 생각하고, 보 청기 구입 결정에 영향을 미치는 다른 요인들을 분석하여 첫 상담 중에 보청기 구입 결정을 예측하고자 하였다.

\section{대상 및 방법}

\section{대 상}

2013년 1월부터 2016년 6월까지 본원 이비인후과에서 양측 난청으로 보청기 상담을 받은 성인 956명(여 507명, 나이 66.5 \pm 12.1 세)을 대상으로 청력검사 결과(청력 역치 4분법 평균값, 이명의 유무, 난청의 유형)와 문진 중 파악하는 직업유무와 직업환경 중 소음노출 여부, 사회활동(상, 중, 하) 정도의 기초 정보를 의무기록을 통하여 후향적으로 분석하였으며, 연구 의 진행은 본원 윤리위원회의 심의(No. VC16RISI0141)를 받 은 후 이루어졌다.

\section{방 법}

본원에서 보청기 상담을 시행하는 과정을 간단히 요약하면 다음과 같다.

1) 보청기가 필요한 난청 환자의 난청 정도에 적합하도록 피팅한 보청기를 끼워주고 실제 얼마나 잘 들리고 어떻게 들 리는지를 체험하게 한 후 대화를 통해 어음 분별 상태를 확 인한다.

2) 이명이 있는 경우 차폐여부를 확인하고 불편함 등을 상 담한다.

3) 가격과 옵션을 설명한다.
4) 질문사항에 대답한다.

5) 결정할 시간을 준다.

이 과정은 일반적으로 15 분 정도 소요되며 질문시간에 5 분 정도의 여유를 추가하여 20 분을 첫 상담 제한시간으로 정하 였다. 시간이 길어질 때, 상담내용이 바뀌지는 않고 주로 질문 과 답변 시간이 길어지거나 결정을 못해서 시간이 지연되었다.

상담 시간에 제한을 두지 않은 경우와 20분 이내로 제한한 경우에서 보청기 보유율에 차이가 있는지를 분석하였고, 사회 활동 정도는 대화가 필요한 직업이 있는 경우를 '상', 직업은 없 어도 참석하는 모임이 있는 경우를 '중', 대화를 거의 하지 않 는 직업이나 가족 외에는 대화를 하지 않는 경우를 '하로 정 하였다. 보청기 구입 결정을 하지 못하는 이유는 다음과 같은 범주에 해당하는지로 구분하였다.

1) 가족의 권유로 상담은 받았으나 본인이 사용의지가 없는 경우, 거부감, 감정적으로 싫은 경우

2) 사용의지는 있는데 불편함으로 결정하지 못하는 경우

3) 경제적인 이유(청각장애 지원이나 산재 보험에서 보조 결 정이 나면 결정한다는 경우, 가족과 상의 후, 혹은 다른 기관 과 가격 비교 후 결정한다는 경우에 해당함)

4) 일단은 다음에 결정하기로 미루는 경우

5) 원인미상

\section{통 계}

연속형 변수와 범주형 변수에 대해서는 independent $\mathrm{t}-$ test와 chi-square test 혹은 Fisher's exact test를 이용하여 두 군 간의 차이를 검정하였다. 보청기의 선택에 영향을 주는 변수를 알아보기 위해 단변량 logistic regression 분석을 통 해 각 변수들의 odds ratio를 구하였고, 유의미한 결과를 바 탕으로 $(p$-value<0.05) 다변량 logistic regression 및 모형 설명력에 해당되는 area under receiver operating characteristic(ROC) 값을 구하였다. 통계는 SPSS version 21.0(SPSS Inc., Chicago, IL, USA)과 SAS version 9.4(SAS Inc., Cary, $\mathrm{NC}, \mathrm{USA}$ )를 이용하였고, $p$-value $<0.05$ 를 통계적으로 유의 미하다고 평가하였다.

\section{결 과}

2013년 1월부터 2016년 6월까지 본원 이비인후과에서 양 측 난청으로 보청기 상담을 받은 성인 956명(여 507명, 나이 $66.5 \pm 12.1$ 세) 중 $48.64 \%$ 인 465 명이 첫 상담에서 보청기를 선 택하였다. 상담 시간에 제한을 두지 않았던 550명(남 265명, 나이 67.4 \pm 12.5 세) 중 274 명이, 상담 시간을 20 분 이내로 제한 하던 406명(남 184명, 나이 68.8 111.9 세) 중 191명이 보청기를 
Table 1. Baseline characteristic of hearing loss patients according to time limitation

\begin{tabular}{|c|c|c|c|}
\hline Characteristics & Without time limitation $(n=550)$ & With time limitation $(n=406)$ & $\mathrm{p}$ value \\
\hline Age (year) & $67.42 \pm 12.51$ & $68.79 \pm 11.91$ & 0.089 \\
\hline Sex (male, \%) & $265(48.2)$ & $184(45.3)$ & 0.381 \\
\hline Social status & & & $<0.001$ \\
\hline High & $92(16.7)$ & $99(24.4)$ & \\
\hline Middle & $300(54.6)$ & $93(22.9)$ & \\
\hline Low & $158(28.7)$ & $214(52.7)$ & \\
\hline Occupation (\%) & $101(18.4)$ & $104(25.6)$ & 0.007 \\
\hline Noise status (\%) & $42(7.6)$ & $18(4.4)$ & 0.044 \\
\hline \multicolumn{4}{|l|}{ Pure tone average $(\mathrm{dB})$} \\
\hline Left & $62.83 \pm 20.40$ & $64.95 \pm 19.45$ & 0.105 \\
\hline Right & $61.52 \pm 19.31$ & $62.67 \pm 19.45$ & 0.366 \\
\hline Type of HI (left) & & & $<0.001$ \\
\hline Sensorineural & $390(70.9)$ & $343(84.5)$ & \\
\hline Conductive & $155(28.2)$ & $54(13.3)$ & \\
\hline Mixed & $5(0.9)$ & $9(2.2)$ & \\
\hline Type of HI (right) & & & $<0.001$ \\
\hline Sensorineural & $410(74.6)$ & $346(85.2)$ & \\
\hline Conductive & $137(24.9)$ & $52(12.8)$ & \\
\hline Mixed & $3(0.6)$ & $8(2.0)$ & \\
\hline Tinnitus (left) & $184(33.5)$ & $134(33.0)$ & 0.884 \\
\hline Tinnitus (right) & $183(33.3)$ & $127(31.3)$ & 0.516 \\
\hline Hearing aid uptake (\%) & $274(49.8)$ & $191(47.0)$ & 0.396 \\
\hline
\end{tabular}

HI: hearing impairment

Table 2. Baseline characteristics according to HA uptake

\begin{tabular}{|c|c|c|c|}
\hline Characteristics & HA refused $(n=491)$ & HA purchased $(n=465)$ & $p$ value \\
\hline Age (year) & $67.20 \pm 12.09$ & $68.84 \pm 12.42$ & 0.039 \\
\hline Sex (male, \%) & $234(47.7)$ & $215(46.2)$ & 0.660 \\
\hline Social status & & & $<0.001$ \\
\hline High & $99(20.2)$ & $92(19.8)$ & \\
\hline Middle & $158(32.2)$ & $235(50.5)$ & \\
\hline Low & $234(47.7)$ & $138(29.7)$ & \\
\hline Occupation (\%) & $104(21.2)$ & $101(21.7)$ & 0.839 \\
\hline Noise status (\%) & $28(5.7)$ & $32(6.9)$ & 0.453 \\
\hline \multicolumn{4}{|l|}{ Pure tone average (dB) } \\
\hline Left & $62.34 \pm 20.84$ & $65.19 \pm 19.02$ & 0.027 \\
\hline Right & $60.63 \pm 19.77$ & $63.46 \pm 18.85$ & 0.024 \\
\hline Type of HI (left) & & & 0.268 \\
\hline Sensorineural & $378(77.0)$ & $355(76.3)$ & \\
\hline Conductive & $103(21.0)$ & $106(22.8)$ & \\
\hline Mixed & $10(2.0)$ & $4(0.9)$ & \\
\hline Type of HI (right) & & & 0.117 \\
\hline Sensorineural & $388(79.0)$ & $369(79.1)$ & \\
\hline Conductive & $94(19.1)$ & $95(20.4)$ & \\
\hline Mixed & $9(1.8)$ & $2(0.4)$ & \\
\hline Tinnitus (left) & $181(36.9)$ & $137(29.5)$ & 0.015 \\
\hline Tinnitus (right) & $178(36.3)$ & $132(28.4)$ & 0.009 \\
\hline With time limitation & $215(43.8)$ & $191(41.1)$ & 0.396 \\
\hline Time (minutes) & $5.79 \pm 6.92$ & $6.95 \pm 8.85$ & 0.026 \\
\hline
\end{tabular}

HA: hearing aid, HI: hearing impairment 
Korean J Otorhinolaryngol-Head Neck Surg I 2017;60(1):13-8

Table 3. Association between hearing aids decision and baseline variables

\begin{tabular}{|c|c|c|c|c|}
\hline \multirow{2}{*}{ Characteristics } & \multicolumn{2}{|c|}{ Univariate } & \multicolumn{2}{|c|}{ Multivariate } \\
\hline & OR $(95 \% \mathrm{Cl})$ & $p$ value & OR $(95 \% \mathrm{Cl})$ & $p$ value \\
\hline Age (year) & $1.01(1.00-1.02)$ & 0.040 & $1.03(1.02-1.05)$ & $<0.001$ \\
\hline Sex (male) & $0.95(0.73-1.22)$ & 0.660 & & \\
\hline Social status & & $<0.001$ & & $<0.001$ \\
\hline High & 1 (reference) & & 1 (reference) & \\
\hline Middle & $1.60(1.13-2.27)$ & 0.008 & $1.36(0.91-2.04)$ & 0.132 \\
\hline Low & $0.64(0.45-0.90)$ & 0.012 & $0.31(0.20-0.49)$ & $<0.001$ \\
\hline Occupation & $0.97(0.71-1.32)$ & 0.839 & & \\
\hline Noise status & $1.22(0.72-2.06)$ & 0.453 & & \\
\hline \multicolumn{5}{|l|}{ Pure tone average } \\
\hline Left & $1.007(1.001-1.014)$ & 0.028 & $1.006(0.999-1.014)$ & 0.107 \\
\hline Right & $1.008(1.001-1.014)$ & 0.024 & $1.007(0.999-1.015)$ & 0.085 \\
\hline Type (left) & & 0.288 & & \\
\hline Sensorineural & 1 (reference) & & & \\
\hline Conductive & $1.10(0.81-1.49)$ & 0.560 & & \\
\hline Mixed & $0.43(0.13-1.37)$ & 0.153 & & \\
\hline Type (right) & & 0.163 & & \\
\hline Sensorineural & 1 (reference) & & & \\
\hline Conductive & $1.07(0.78-1.47)$ & 0.696 & & \\
\hline Mixed & $0.23(0.05-1.09)$ & 0.065 & & \\
\hline Tinnitus (left) & $0.72(0.55-0.94)$ & 0.015 & $0.85(0.60-1.20)$ & 0.356 \\
\hline Tinnitus (right) & $0.70(0.53-0.92)$ & 0.010 & $0.82(0.58-1.17)$ & 0.279 \\
\hline Time limitation & $0.90(0.69-1.16)$ & 0.397 & & \\
\hline Time (minutes) & $1.02(1.00-1.04)$ & 0.025 & $1.04(1.02-1.06)$ & $<0.001$ \\
\hline
\end{tabular}

$\mathrm{Cl}$ : confidence interval, OR: odds ratio

Table 4. Final model for predicting hearing aid decision

\begin{tabular}{|c|c|c|c|}
\hline Parameters & $\begin{array}{c}\text { Beta } \\
\text { coefficient }\end{array}$ & OR $(95 \% \mathrm{Cl})$ & $p$ value \\
\hline Intercept & -0.6281 & & 0.016 \\
\hline Social status & & & $<0.001$ \\
\hline High & (reference) & 1 (reference) & \\
\hline Middle & 0.4969 & $1.64(1.16-2.34)$ & 0.006 \\
\hline Low & -0.5184 & $0.60(0.42-0.85)$ & 0.005 \\
\hline Pure tone (right) & 0.011 & $1.01(1.00-1.02)$ & 0.002 \\
\hline Tinnitus (right) & -0.3566 & $0.70(0.53-0.93)$ & 0.013 \\
\hline
\end{tabular}

결정하여 각각 $49.81 \%$ 와 $47.04 \%$ 로 두 군 사이에 유의한 차 이는 없었다 $(p=0.396)$ (Table 1).

20 분 이내라는 제한을 두고 측정한 첫 상담 시간은 $14.96 \pm$ 4.38분이었으며, 보청기를 선택하지 않은 군은 $5.79 \pm 6.92$ 분, 선택한 군은 $6.95 \pm 8.85$ 분으로 유의한 차이가 있었다 $(p=0.026)$ (Table 2).

Table 2에서 대상 난청 환자들의 기본 정보들을 보청기를 선
택하지 않은 군과 선택한 군으로 나누어 비교하였다. 보청기 를 선택한 군의 나이가 많았고 $(p=0.039)$, 사회활동 정도는 의 미 있는 차이를 보였다 $(p<0.001)$. 청력 역치값은 보청기를 선 택한 군에서 유의하게 높았고(좌측 $p=0.028$, 우측 $p=0.024$ ), 이명은 의미 있는 차이를 보이는데 보청기를 선택한 군에서 이명이 있는 경우가 오히려 적은 것으로 나타났다.

Table 3은 로지스틱 회귀분석방법으로 각 변수와 보청기 선택 유무에 어떤 영향을 주는지를 odds ratio로 확인한 결 과로 우선 단변량 분석에서 의미 있게 나온 값들만을 가지고 다변량 분석을 하였다. 다변량 모형의 가정 위배 여부를 확인 하는 동질성 검정으로 Hosmer-Lemeshow test를 시행하였 으며, 0.05보다 클 때 가정을 위배하지 않는다는 의미로 0.518 값에 의해 다변량 모형의 가정을 위배하지 않는다는 것을 확 인할 수 있었다. 유의미한 변수로 나타난 결과만을 가지고 최 종 모형을 만들었고, Table 4에서 총 3개의 변수(social status, right side pure tone, right side tinnitus)를 이용한 모형의 함 수를 다음과 같이 얻었다.

Hearing aid uptake probability=Exp (w)/[1+Exp (w)], $\mathrm{w}=-0.6281+0.4969 \times($ middle class $)-0.5184 \times($ low class $)+$ 


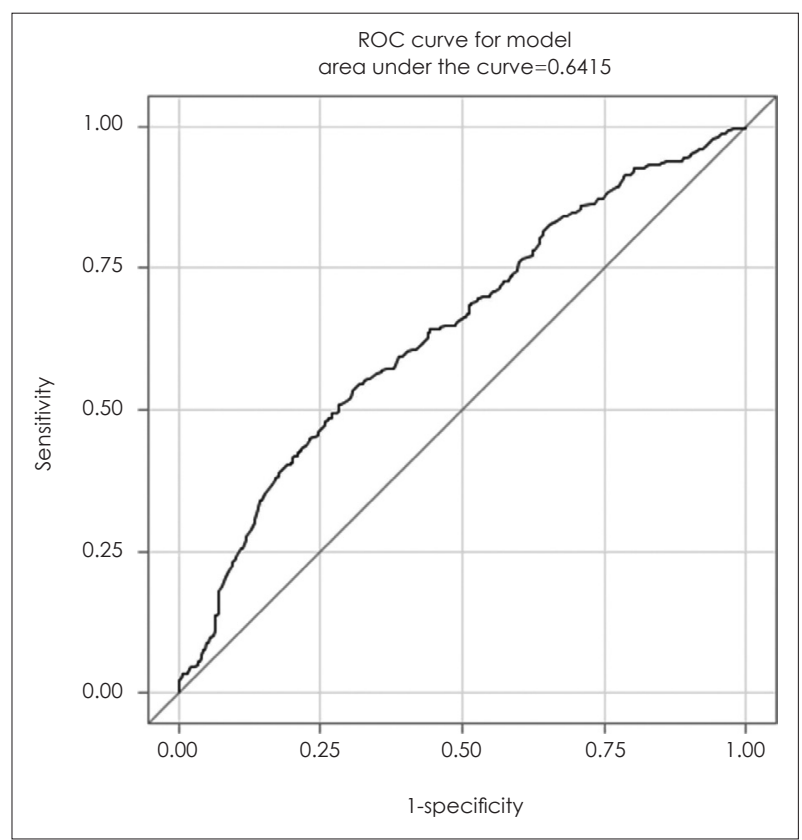

Fig. 1. The plot of area under receiver operating characteristic (ROC) expresses the model explanation power to be 0.6415 .

$0.011 \times$ (right pure tone) $-0.3566 \times($ right tinnitus $)$

예를 들어, $\mathrm{A}$ 환자가 사회활동이 middle class이고 청력 역 치값이 $70 \mathrm{~dB}$ 에 이명이 없는 경우, $\mathrm{w}=0.6388, \mathrm{Prob}=0.654482$ 이며, B 환자는 사회활동이 low class이고 청력 역치 값이 80 $\mathrm{dB}$, 이명이 없는 경우, $\mathrm{w}=-0.2665, \mathrm{Prob}=0.433767$ 이다.

모형 설명력을 나타내는 area under ROC curve(AUC) 값은 0.6415 로 $64.15 \%$ 의 예측 정확도(Fig. 1)를 가지고 A 환자가 보청기를 선택할 확률은 약 $65.44 \%, \mathrm{~B}$ 환자가 선택할 확률은 43.37\% 정도라고 예상할 수 있다.

Fig. 1의 ROC는 민감도와 특이도가 어떤 관계를 갖고 변 하는지 2차원 평면상에서 표현한 것으로 $\mathrm{ROC}$ 곡선 아래의 면적(area under ROC curve)이 넓을수록 좋은 진단방법 혹 은 모형 설명력이 좋다고 할 수 있다.

보청기를 선택하지 않는 이유는 경제적인 이유(53.56\%)가 가장 많았고, 가족의 권유로 상담은 받았으나 본인이 사용의 지가 없는 경우와 거부감, 즉 감정적으로 싫은 경우(20.98\%), 원인미상이거나 복합적인 경우(13.64\%), 다음에 결정하기로 일단 미루는 경우 $(8.55 \%)$, 사용의지는 있는데 불편함으로 결 정하지 못하는 경우 $(3.25 \%)$ 순이었다.

\section{고 찰}

보청기 상담은 맞춤 전 과정에 걸쳐 이루어지며,") 본 연구 에서 측정한 부분은 초기 첫 상담 시간이다. 첫 상담의 목적 은 충분한 정보를 제공하여 환자로 하여금 보청기를 적절히
선택할 수 있게 하는 것이다. 보청기 선택의 주체는 난청 환 자 자신이 되어야 하며 이는 구입 결정 이후에도 지속사용에 중요한 변수이다. 보청기 선택에서는 비 청각학적인 요소가 중요하며, ${ }^{8}$ 보청기 구입 결정에 상담하는 임상의나 청각사와 의 관계가 중요하고 ${ }^{9}$ 대상이 기꺼이 보청기를 구매할 의향이 있는지가 최종 결정에 가장 중요한 변수라 하였다. ${ }^{10)}$ 보청기 를 성공적으로 사용하기 위해서는 청각학적인 요소 중에 난 청의 정도가 중요하고, 비 청각학적인 요소는 복합적이지만 보청기에 대한 감정 측면의 긍정적 태도(attitude)가 가장 중요 하다고 알려져 있다. ${ }^{11)}$ 보청기를 선택하는 일련의 과정 중 첫 시작은 자신이 불편함을 인지하여 해결방법을 찾고 스스로 보청기를 선택하는 의도(intension)가 선행되어야 한다. ${ }^{12)}$

본 연구를 통해서도 첫 상담 과정 중 보청기 구입을 방해하 는 요인들로 경제적인 문제 외에 부정적인 감정 즉, stigma가 중요하였다. 친구나 가족 같은 주위사람들의 부정적인 영향 이 감정적인 부분으로 나타나는데, 상담으로 약간은 해소가 될 수 있으나 근본적인 해결은 어려웠다. 본인이 난청의 불편 을 감지하지 못하거나 난청의 정도가 심하지 않다고 생각하지 만 가족의 권유에 의해 병원을 내원한 경우, 환자가 의사소 통이 중요하지 않은 상황에 있거나 주위에서 환자의 난청에 적 응한 경우에는 보청기를 선택하더라도 착용과 관련된 불편 함 때문에 사용을 중단할 가능성이 높았다.

난청을 노화현상으로 여기고 수동적인 수용상태(acceptance), 즉 난청을 해결하려는 의지가 없는 경우에도 치매와 의 연관성을 설명하고 보청기 사용을 권유할 수 있으나 잘 받아들여지지 않았다. 난청 환자가 보청기를 착용해 보았을 때 도움이 안 된다고 느끼거나 음질이 마음에 들지 않고 소 음이 불편하다고 호소할 때가 있다. 이는 난청 문제가 해소되 는 혜택보다는 불편함을 더 크게 느껴 보청기를 거부하는 경 우이다. 반면 시력이나 손동작의 문제로 작은 보청기를 잘 다 루지 못하는 경우나 인지나 건강 문제가 있을 때 협조가 잘 되는 보호자를 대상으로 상담을 하면 보청기 선택에 도움이 되었다.

보청기를 청력 역치에 맞게 피팅하여 끼워주고 대화를 하 면서 환자의 반응을 보고, 환자들 대부분이 보이는 보청기에 대한 부정적인 반응은 상담을 통해 개선하고자 하였다. 환자 본인이 보청기를 끼고 잘 들리면 필요성을 느끼게 되는데 처 음부터 보청기를 하고자 내원한 환자가 아닌 경우, 보청기 구 입 결정에는 감정적인 영역과 경제적인 문제가 있다. 본인이 보청기가 전혀 필요 없다고 생각하는 경우 상담만으로는 이 문제를 해결하기 어려우며, 보청기가 필요하다고는 느끼는데 감정적으로 싫은 경우는 상담이 도움이 될 수 있었다. 초소형 보청기나 고막형 보청기를 이용하여 외부에서 보이지 않는다 
는 사실과 개방형 보청기도 착용시에는 남의 눈에 잘 띄지 않 는다는 것을 설명하였다. 보청기의 필요성을 알지만 경제적 인 문제가 장벽인 경우는 오랜 상담이 도움이 되지 않았다. 경 제적인 보조 방법을 간단히 알려주는 것으로 상담을 종료하 였다.

보청기를 사용하지 않을 대상을 설득해서 구입만 하게 하 는 것은 반환 문제나 구입만 하고 사용하지 않는 비 이용자 (nonuser) 문제를 가져오므로, 사용하기 꺼려 하거나 사용 안 할 것이 예상되는 환자를 장시간 상담을 통해 보청기를 구입 하게 하는 것은 좋지 않다고 생각한다. 잘못 알고 있는 사실 을 상담을 통해 교정해 주며, 보청기를 하는 것이 향후 스스 로에게 도움이 된다고 생각하여, 스스로 선택하게 하고 지속 적으로 잘 사용할 수 있도록 독려하는 것이 상담의 목적이다. 임상에서 청력과 환자의 건강 상태를 고려하여 보청기를 시도해 볼 것을 권유하면 환자 혹은 보호자가 결정은 하게 되겠지만, 청각사나 이비인후과 의사가 어떤 방식으로 권유 하는지도 그 결정에 영향을 미쳤다. 난청의 정도가 심해지고 난청의 기간이 길어질수록 보청기에 적응하기 힘들고 난청을 방치하면 생길 수 있는 문제를 설명하는 데 결정의 주체가 환 자 자신임을 강조하였다.

본 연구에서 보청기 첫 상담 중 얻을 수 있는 정보 중 사회 활동정도, 청력 역치값, 이명의 유무는 보청기 선택을 예측 하는 데 복합적으로 작용하며 $64 \%$ 의 예측 정확도를 기대할 수 있으나, 다른 변수들의 복합적인 영향력을 모두 예상하기 는 어려웠다. 이명을 동반한 난청 환자들에게 보청기는 이명 의 치료에 효과를 기대할 수 있다고 알려져 있으나, ${ }^{13)}$ 본 연구 에서는 보청기를 선택한 군에서 이명이 있는 경우가 오히려 적 은 것으로 나타났다.

또한 이 연구는 보청기에 대한 감정적인 부분과 경제력(구매 력)처럼 상담 과정 중 측정이 어려운 변수들이 복합적으로 작 용한다는 것을 간접적으로 시사하는데, 이러한 문제는 상담 을 오래 하더라도 예측 가능성이 올라가지 않고 상담을 통해 바꿀 수 있는 부분이 제한적이었다. 따라서 불필요한 장시간 의 상담 시간을 줄이기 위해서는 청각학적, 비 청각학적 요 인을 파악한 이후에는 적절한 정보를 주고 선택을 하도록 따
로 선택의 시간을 주는 편이 좋다고 생각한다.

보청기를 결정하지 못하는 이유는 개인별로 다양하고 환 자가 보청기의 필요성을 못 느끼는 경우나 경제적인 문제 등 은 상담을 오래한다고 결정이 잘 바뀌지 않았으므로, 상담 시 간을 적절히 설정하는 것이 난청 보청기 클리닉의 효율적인 운 영방법이라 생각한다.

\section{Acknowledgments}

The statistical consultation was supported by a grant of the Korea Health Technology R\&D Project through the Korea Health Industry Development Institute (KHIDI), funded by the Ministry of Health \& Welfare, Republic of Korea (grant number: HI14C1062).

\section{REFERENCES}

1) Kochkin S. Reducing hearing instrument returns with consumer education. Hear Rev 1999;6(10):18-20.

2) Kemker BE, Holmes AE. Analysis of prefitting versus postfitting hearing aid orientation using the glasgow hearing aid benefit profile (GHABP). J Am Acad Audiol 2004;15(4):311-23.

3) Searchfield GD, Kaur M, Martin WH. Hearing aids as an adjunct to counseling: tinnitus patients who choose amplification do better than those that don't. Int J Audiol 2010;49(8):574-9.

4) Cho YS. Management of hearing aids clinic. Korean J OtorhinolaryngolHead Neck Surg 2010;53(6):333-9.

5) Blood IM. The hearing aid effect: challenges for counseling. J Rehabil 1997;63(4):59-62.

6) Moon SK, Lee JW, Choung YH, Park K. Clinical analysis of hearing aid failure. Korean J Otolaryngol-Head Neck Surg 2005;48(1):13-7.

7) Oh SH, Lee J. General framework of hearing aid fitting management. J Audiol Otol 2016;20(1):1-7.

8) Meyer C, Hickson L, Lovelock K, Lampert M, Khan A. An investigation of factors that influence help-seeking for hearing impairment in older adults. Int J Audiol 2014;53 Suppl 1:S3-17.

9) Poost-Foroosh L, Jennings MB, Shaw L, Meston CN, Cheesman MF. Factors in client-clinician interaction that influence hearing aid adoption. Trends Amplif 2011;15(3):127-39.

10) Poost-Foroosh L, Jennings MB, Cheesman MF. Comparisons of client and clinician views of the importance of factors in client-clinician interaction in hearing aid purchase decisions. J Am Acad Audiol 2015;26(3):247-59.

11) Hickson L, Meyer C, Lovelock K, Lampert M, Khan A. Factors associated with success with hearing aids in older adults. Int J Audiol 2014;53 Suppl 1:S18-27.

12) Meister H, Grugel L, Meis M. Intention to use hearing aids: a survey based on the theory of planned behavior. Patient Prefer Adherence 2014:8:1265-75.

13) Lee YC, Byun JY, Shin IH, Park MS. The effectiveness of the hearing aid in hearing loss with tinnitus. Korean J Otorhinolaryngol-Head Neck Surg 2008;51(11):967-72. 